\title{
A Worrisome PICC Line Complication in a Premature Newborn: Knotted Catheter
}

\author{
Fatma Hilal Yilmaz ${ }^{1}$ (D) Ayhan Çeri $^{2}$
}

Received: 31 March 2021 / Accepted: 20 May 2021 / Published online: 9 June 2021

(C) Dr. K C Chaudhuri Foundation 2021

To the Editor: Peripherally inserted central catheters (PICCs) are a common way of intravenous access to provide long-term treatment and parenteral nutrition in preterm and term infants $[1,2]$. A 30-wk-5-d-old baby with a birth weight of $1770 \mathrm{~g}$ was tranferred to neonatal intensive care unit after birth on the presumed diagnosis of prematurity and respiratory distress. The umbilical vein catheter was placed initially and an antibiotics regimen of ampicillin plus gentamycin and total parenteral nutrition were initiated. Also respiratory support to the patient was given with nasal continuous positive airway pressure. On the 11th day of his hospitalization, the patient's antibiotic treatment and partial parenteral nutrition were still continuing when the umbilical vein catheter got spontaneously dislocated. So, a $24 \mathrm{G}$ (2 Fr) PICC line was placed to the right cephalic vein at $16 \mathrm{~cm}$ length. After locating the tip of the catheter by direct radiography, and assuring that it was correctly placed, the heparinized PICC line was started to be used. Three days later, the infusion pump gave an alarm for sudden occlusion, and the fluid flow was stopped. Although no intervention was performed after placing it, the catheter was seen to be knotted on direct radiography. So it was removed by a careful and gentle pulling out process. The resting treatment was completed via peripheral vein access in the following days and the patient was discharged with full recovery on the postnatal 35th day. By reporting this case, we want to being to the clinician's attention that with the increasing frequency of PICC placement in newborns, a clinician should take into account knotting possibility of PICC while formulating the differential diagnosis when faced up to a malfunctioning line, in order to prevent potentially associated complications.

\section{Declarations}

Conflict of Interest None.

\section{References}

1. Ainsworth SB, McGuire W. Peripherally inserted central catheters vs peripheral cannulas for delivering parenteral nutrition in neonates. JAMA. 2016;315:2612-3.

2. McCay AS, Elliot EC, Walden M. Videos in clinical medicine. PICC placement in the neonate. N Engl J Med. 2014;370:e17.

Publisher's Note Springer Nature remains neutral with regard to jurisdictional claims in published maps and institutional affiliations.

Fatma Hilal Yilmaz

f.h.yilmaz@hotmail.com

1 Department of Neonatology, Dr Ali Kemal Belviranli Hospital for Obstetrics and Pediatrics, 42285 Konya, Turkey

2 Department of Child Health and Disease, Dr Ali Kemal Belviranli Hospital for Obstetrics and Pediatrics, Konya, Turkey 